\title{
RECORD OF MEETINGS OF THE EDINBURGH MATHEMATICAL SOCIETY
}

\author{
SIXTY-FIFTH SESSION, 1946-47.
}

November 1 st.

Presidential address, "Augustus De Morgan," by Dr J. Mackie. Read by title :"The analytical continuation of the Riesz-Riemann-Liouville integral" by E. T. Copsun; " Pseudo-harmonic potential theory," by A. G. WALKER; "Expansions in terms of parabolic cylinder functions," by T. M. ChERRY; "A generalisation of minimal variation," by J. G. FreEman.

December 6th.

Maclaurin Centenary Meeting. Principal speakers : Dr R. ScillapP and Professor H. W. Turnbull. Read by title:- "Aronhold's theorems on bitangents," by J. H. GraCe; "On certain discontinuous, wave functions," by Dr A. Erdély r.

January 17 th.

“Plane involutions," by Dr L. M. Brown. Read by title :-“"The extension of a formula by Cayley to symmetric determinants,' by LARS Gardixg; "Symmetric determinants and the Cayley and Capelli operators," by H. W. TuRnblLL; "The variation in densities resulting from a circular density pattern of which the centre is normally and circularly distributed," by M. H. QuenouiLle.

\section{February 7 th.}

"Some remarks on matrix differentiation," by Professor A. C. Aitren; "Discontinuous wave functions," by Dir A. Erdély r.

\section{March 7 th.}

"Latent roots and eigenfunctions," by Professor E. T. Copson.

May 2nd.

Spaces of recurrent curvature," by Professor H. S. Ruse. Read by title:-- "On a system of equations," by H. Sircar.

June 7th, at St Andrews.

"The addition of random vectors," by Mr R. D. LokD; "Symmetric determinants and the Cayley and Capelli operators," by Professor H. W. Tornbull. Read by title :"On non-associative systems," by A. RoBInson ; "On a method of summing divergent sequences," by S. C. Mirra ; "On a class of arrangements," by C. Radhakrishina RaO ; "An inversion formula for the generalised Laplace transform," by R. S. Varma.

\section{SiXty-SIXTH Session, 1947-48.}

November 7th.

Presential Address, "Lagrange multipliers," by Dr R. P. GrLlespie. Read by title:- "On a problem of alternating decomposition," by Hwa Chung LeE ; "On com. pounds of simple sets of polynomials," by R. H. MAKAR ; "On absolute Lambert sums," by Aurel Wintake. 
December 5 th.

"The representation of functions by series," by Professor J.. M. Whitraker.

January 16th.

"Linear independence of functions," by MrF. F. Bonsall; "The photo-electric Fourier transformer," by Mr J. B. SмIтн. Read by title :-_"The effect of viscosity on wave motion," by M. RothMan; "A priori Laplace transformations of linear differential equations," by Aurel Wintner.

February 6th.

Discussion on "Statistics as an aid to the examiner," led by Mr G. REITH.

March 5th.

"Symposium on probability"-questions answered by Professor A. C. Arrken and Dr W. O. Kermack.

May 7 th.

" The structure of globular clusters," by Professor W. M. H. Greaves. Read by title:- "The absolute Cesàro summability of the successively derived allied series of a Fourier series," by R. Mohanty ; "On a Tauberian theorem of G. Ricci," by C. T. RAJAGopal, ; A note on Stone's Boolean ring of n-dimensions," by R. Shukla; "Equal sums of like powers," by E. M. Wright.

June 5th, at St Andrews.

"An approximate method of evaluating certain ts pes of surface integral," by $\mathrm{Dr}$ J. M. JACKSON ; "Self transformations of algebraic surfaces," by Mr L. S. GodDARD. 